九州大学学術情報リポジトリ

Kyushu University Institutional Repository

\title{
Read Range Optimization of Low Frequency RFID System in Hostile Environmental Conditions by Using RSM Approach
}

Choudhary, Shilpa

Department of Electronics and Communication Engineering, G L Bajaj Institute of Technology and Management

Sharma, Abhishek

Department of Mechanical Engineering, G L Bajaj Institute of Technology and Management

Srivastava, Kashish

Department of Electronics and Communication Engineering, G L Bajaj Institute of Technology and Management

Purohit, Hemant

Department of Electronics and Communication Engineering, Jodhpur Institute of Engineering and Technology

他

https://doi.org/10.5109/4068619

出版情報：Evergreen. 7 (3)，pp.396-403，2020-09. 九州大学グリーンテクノロジー研究教育センター バージョン：

権利関係 : 


\title{
Read Range Optimization of Low Frequency RFID System in Hostile Environmental Conditions by Using RSM Approach
}

\author{
Shilpa Choudhary ${ }^{1 *}$, Abhishek Sharma ${ }^{2}$, Kashish Srivastava ${ }^{3}$, Hemant Purohit ${ }^{4}$, \\ Mudita Vats ${ }^{5}$ \\ ${ }^{1}$ Department of Electronics and Communication Engineering, G L Bajaj Institute of Technology and \\ Management, Greater Noida, UP, India \\ ${ }^{2}$ Department of Mechanical Engineering, G L Bajaj Institute of Technology and Management, Greater \\ Noida, UP, India \\ ${ }^{3}$ Department of Electronics and Communication Engineering, G L Bajaj Institute of Technology and \\ Management, Greater Noida, UP, India \\ ${ }^{4}$ Department of Electronics and Communication Engineering, Jodhpur Institute of Engineering and \\ Technology, Jodhpur, Rajasthan, India \\ ${ }^{5}$ Department of Electronics and Communication Engineering, G L Bajaj Institute of Technology and \\ Management, Greater Noida, UP, India
}

*Author to whom correspondence should be addressed:

E-mail: shilpadchoudhary@gmail.com

(Received May 5, 2019; Revised August 24, 2020; accepted September 23, 2020).

\begin{abstract}
RFID system plays a major role in asset tracking but its performance may get challenged when it has to work in extreme atmospheric conditions. RFID system can play an important role in military or defense purpose to track the land mines, military containers etc. Keeping these things in mind, this research work was carried out for the military areas which are situated in arid and semiarid regions. In this research work, experimental investigation, statistical analysis and optimization of the low frequency RFID system read range has been carried out with respect to four major input parameters i.e. varying sandy soil grain sizes $(0.45 \mathrm{~mm}, 0.78 \mathrm{~mm}, 1.18$ $\mathrm{mm}, 1.6 \mathrm{~mm}$ and $2 \mathrm{~mm}$ ) which is present in between RFID reader and tag, temperature $\left(15^{\circ} \mathrm{C}\right.$ to $50{ }^{\circ} \mathrm{C}$ ), humidity (35\%RH to $70 \% \mathrm{RH}$ ) and sandy soil layer thickness $(0 \mathrm{~mm}$ to $90 \mathrm{~mm}$ ). Here the optimization is being done by using response surface methodology (RSM). From the investigations and optimization it was found that maximum value of read range which the LF RFID system can attain is $118.14 \mathrm{~mm}$ for the optimum combination of input variables i.e. temperature, soil layer thickness, relative humidity and soil grain size were found to be $25.606{ }^{\circ} \mathrm{C}, 0 \mathrm{~mm}, 35 \%$ and $2 \mathrm{~mm}$ respectively.
\end{abstract}

Keywords: RFID; RSM; Detectability; Read Range; Tag; Reader.

\section{Introduction}

RFID system is similar to the bar code system which is one of the methods used in automatic identification and data capturing. It uses electromagnetic waves for the transmission of information between the tag and the reader. This system consists of three major parts tag antenna or transponder, reader and microchip, the microchip is used in storing the data and transferring them to the reader to read. RFID system basically collects the data about an object or substance automatically without any manual readings involved in $\mathrm{it}^{1}{ }^{1}$. Due the storage capability and without manual reading requirement this system is being used more frequently as compared to other identification and data capturing method and it can hold more amount of information than bar code system ${ }^{2}$. There are various advantages of RFID tags because of which it is being utilized in various areas of defense, aeronautics, agriculture and even in soil corrosion and location tracking as well as pre-prediction of environmental changes as it is a real-time monitoring system $^{3,4)}$. Advantage of RFID tag is that it is "low budget" and to keep it a low budget system, there is a need for reduction in its manufacturing cost. Due to this reason RFID tag has thin conducting layers with high radiation efficiency. Though from past experiences about this method had shown that the decrement of conducting layer can result into the increment of losses and decrement of efficiency, resulting into weak backscatter power from tag. 
Another beneficial factor of RFID tag is that each RFID sensor has its unique identity and hence the faulty sensor can be located easily. Though it can be used in adverse condition but there are various obstacles that come while the transferring data between the tag and the reader and it could be because of the atmospheric variation which may affect the RFID system parameters and sometime it may result into undetected tag even though it is in readable range of reader. Noise is another essential reason behind the changes in the parameter as it is a wireless communication. This could lead to the errors in the detectability of the tag by the reader.

So keeping these challenging situations in mind, this work mainly considered the effect four parameters i.e. relative humidity, temperature and the presence of different soil layer thickness and its different grain sizes in between the tag and the reader may affect the RFID system performance or the RFID system read range. Investigations were carried out experimentally as well as statistically and the optimization was done by using response surface methodology to find the best value of read range for optimum values of input parameters.

\section{Related Work}

There have been many attempts to study the various factors that can affect the detectability of RFID System. That includes four major parameters i.e. varying temperature, humidity as well as the presences of soil and its different grain sizes that can be encountered in the path between the channel of RFID System tag and reader may affect the system performance. C. Bauer-Reich et al. in their work shows that if the presences of the humidity content get increased by $15 \%$ in the atmosphere it can lead to high attenuation in the channel or even complete loss of the signal and as the amount of water content increases as a result the read range decreases ${ }^{4}$. To reduce the monitoring cost Fangming Deng et al. bring up another idea in which they use RFID sensor and LoRa technology for reading soil environment by real time monitoring in which the RFID sensor consisted of three sections first is communication; second is power management section and third is the digital section and then they found an error percentage of $1.0 \%$ due to the humidity effect when the sensor was in the depth of 60 $\mathrm{cm}$ and the soil moisture content was less than $30 \%$ ). Kirsi Saarinen et al. studied the effect of varying humidity on performance of UHF RFID tag with anisotropic conductive adhesive (ACA) joint. Tag was tested for $85 \% \mathrm{RH}$ to $10 \% \mathrm{RH}$ and $85^{\circ} \mathrm{C}$ to $10^{\circ} \mathrm{C}$ atmospheric conditions. During the experiment different form of failures was observed. They also gave the reason that the variation in the impedance matching of the antenna of tag can be because of the cracks on the antenna due to the chemical or mechanical changes in the ACA joint while testing the RFID system ${ }^{6}$. Sari Linnea Merilampi et al. in their research while testing found that the presence of water molecules in the environment the frequency response and the losses of tag antenna gets affected and the impedance of antenna gets increased from "ideal or matched" impedance and hence it results in the increase in the power coefficient as well as threshold power ${ }^{7)}$. Juvenal Alarcon et al. Juvenal Alarcon et al. proposed a modified tag and they found that if this flexible tag is fixed with a non-metallic object, its performance gets enhanced. ${ }^{8)}$. Sabina Manzari et al. in their research brought a new technique where polymer doped RFID tags were used ${ }^{9)}$. K. Dastoori et al. in his studied the effects of charged particle in the channel between RFID system tag and reader. From the study they observed that these charged particle or dust attenuates the response with respect to the distance between the tag and the reader ${ }^{10)}$. Hong, Yizhi et al. in their work explained that there are millions of dollars' worth of property damage as well injuries and many such incidents occurs due to the pipeline corrosion and to overcome these problems they used RFID tag system. Simultaneously, real time monitoring of outside the pipeline corrosion in wireless communication as these tags are made up of non-metallic substances ${ }^{11)}$. As per the findings of S. Choudhary et al. the read range of RFID system has inverse relation with relative humidity and shows the same effect with respect to temperature if it ranges above $25^{\circ} \mathrm{C}$ and if temperature reduces below $25^{\circ} \mathrm{C}$, read range also decreases with $\mathrm{it}^{12)}$. Mathieu Le Breton el al. worked over the effects on passive RFID tags of $868 \mathrm{MHZ}$ by the meteorological effects in outdoor area. In this investigation they observed about the effect of water on the antenna, heating effects of cables and tags and moisture of tag support and other atmospheric parameters. As a result they found that there is impact of these outdoor meteorological parameters on the passive RFID tags ${ }^{13)}$. Abdulsalam Dukyil et al. worked over a model that is efficiently cost effective and targets to solve two issues regarding the RFID tag designing firstly, in allocating the number of related facilities that should be introduced and secondly, minimizing operational and implementation costing ${ }^{14)}$. Emran Md Amin et al. worked over low budget UHF RFID light sensor and they found that in between 0 to 1000 lux four light intensities can be detected easily ${ }^{15)}$. Jian Ming-Shen et al. in their worked showed that RFID system can be easily and effectively used in automatic management procedures and proposed that fulfilling a consumer's desire is more essential than the cost to some points ${ }^{16)}$. Li Zhenzhong et al. in their work experimentally showed that there is linear relation between the resonant frequency of passive RFID tag and the temperature when the relative humidity is between $50 \%-80 \%$ whereas there is no significant variation in the resonant frequency when there is change in relative humidity while the temperature is kept constant $200{ }^{\circ} \mathrm{C}$ to $800 \mathrm{C}^{17)}$. Jussi Nummela et al. in their practical of studying the effect of low temperature of about $-210^{\circ} \mathrm{C}$ on RFID tag observed that it is feasible to use them even at snow or icy surfaces ${ }^{18)}$. Chonggang Wang et al. found a 
new algorithm of optimization of RFID tags and showed that it shows better reading performance than GEN 2 adaptive $\mathrm{Q}$ algorithm ${ }^{19)}$. Steve E. Watkins et al. in their work propose that RFID system can be used in location markers significantly in outer world rather than just in laboratory ${ }^{20)}$.There are some work performed by Andrea Luvisi et al. that also highlighted the fact about the properties of different soils referring the moisture content in it and their case study says that the clay soil having maximum moisture content had failure in reading the signal received from RFID $\operatorname{tag}^{21)}$. Sérgio Francisco Pichorim et al. observed the performance of RFID system for detecting the moisture of soil mixture containing two solutions and as a result they found that these systems can successfully detect the moisture content and hence can be useful in indicating landslides ${ }^{22)}$. H.S. Pali et al. ${ }^{23)}$, Abhishek Sharma ${ }^{24)}$ and Fachransjah Aliunir et al. ${ }^{25)}$ suggest that RSM technology can be used as the optimization tool with which optimization of system parameters can be done and that too with minimum number of experiment runs.

From the related work it is very much clear that varying atmospheric parameters does affect the performance of RFID system and much of work has already been done to study the effect of various atmospherics parameters on the performance of RFID system but no one have yet optimized the performance parameters in the work. So keeping these challenging situations in mind, this work mainly considered the effect four input parameters i.e. relative humidity (35\%RH to $70 \% \mathrm{RH})$, temperature $\left(15^{\circ} \mathrm{C}\right.$ to $\left.50^{\circ} \mathrm{C}\right)$, the presence of different soil layer thickness $(0 \mathrm{~mm}$ to $90 \mathrm{~mm})$ and its different grain sizes (.45 $\mathrm{mm}$ to $2 \mathrm{~mm}$ ) which may affect the RFID system performance or RRSS (read range in presence of sandy soil). Only these four parameters were considered as input parameters because this research work was basically carried out for arid or semi-arid reason and these four parameters are the major constraints in such reasons. Later the investigations were carried out experimentally as well as statistically and the optimization was done by using response surface methodology to find the best value (maximum value) of RRSS for optimum values of input parameters.

\section{Materials and Methods}

The conceptual model of work is shown in Fig. 1 and its experiment setup is shown in the Fig. 2. It was used to observe the variation in read range in presence of sandy soil (RRSS). Here the read range is the maximum distance between the tag and reader up to which the tag can be detected by the reader. In the experimental setup the RFID module is connected with the computer by using RS-232 interfacing cable. This computer screen will keen on displaying 12 bit ASCII code up to the time tag is in readable range of reader. In this experiment the car jack was used to give smooth vertical movement to the tag over the reader. Up to the time tag is in readable range, computer will show the 12 bit ASCII code and the maximum distance between the tag and the reader after which the tag will become unreadable has been term as read range of RFID system. To measure the RRSS, digital Vernier caliper was used. In this setup a glass chamber was used to simulate the challenging environment conditions (varying temperature, Relative humidity, different soil layer thickness with varying grain size) which were required to carry out the experiment. Varying relative humidity, temperature, soil grain size and soil layer thickness were measured with the help of hygrometer, thermometer, sieves of 5 different sizes and digital Vernier respectively. In this research work, varying temperature, Relative humidity, different soil layer thickness with varying soil grain size were considered as input parameters whose effect has to measure on the output parameter i.e. Read Range in presence of sandy soil (RRSS).

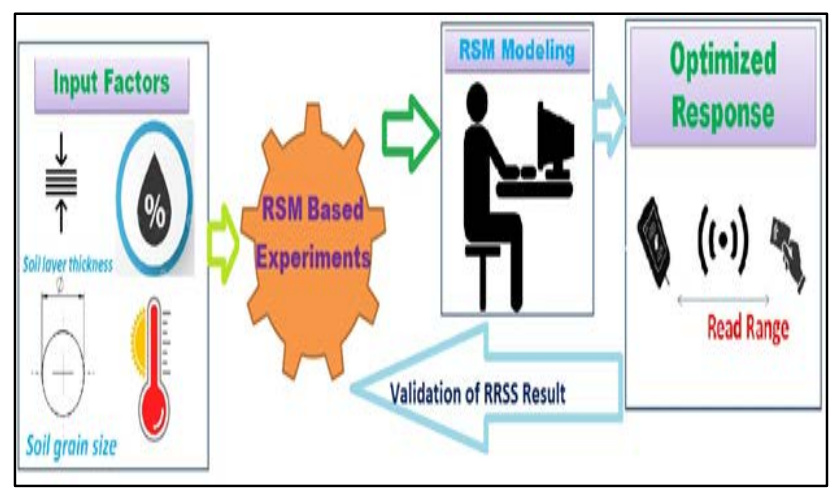

Fig. 1: Conceptual model of work

This research work was mainly focused about the military areas situated in arid or semi-arid region of Rajasthan and the sandy soil is the only soil which covers the major portion in that reason. So the sandy soil was used in this experiment. Sandy soil has poor water retention capacity, high permeability and has poor structure.

Different levels of coding for all these input parameters are shown in Table 1 . This extreme range of input variables was selected as per probable variations in climatic conditions of arid and semi-arid reasons. So practically the existence of these input parameters is not possible above and below the specified range. So, Table 2 is generated after exhaustive experimental run(s). Using these parameters experimental design developed through the statistical tool MINITAB 17. After that experimental results obtained after implementing the CCRD were stated in Table 3. Centre value of the process parameters were taken as per the climatic conditions available for most of the time throughout the year. ANOVA was applied on statistical model, $\mathrm{R}^{2}$ value for Read Range in presence of sandy soil was found to be $98.93 \%$. 


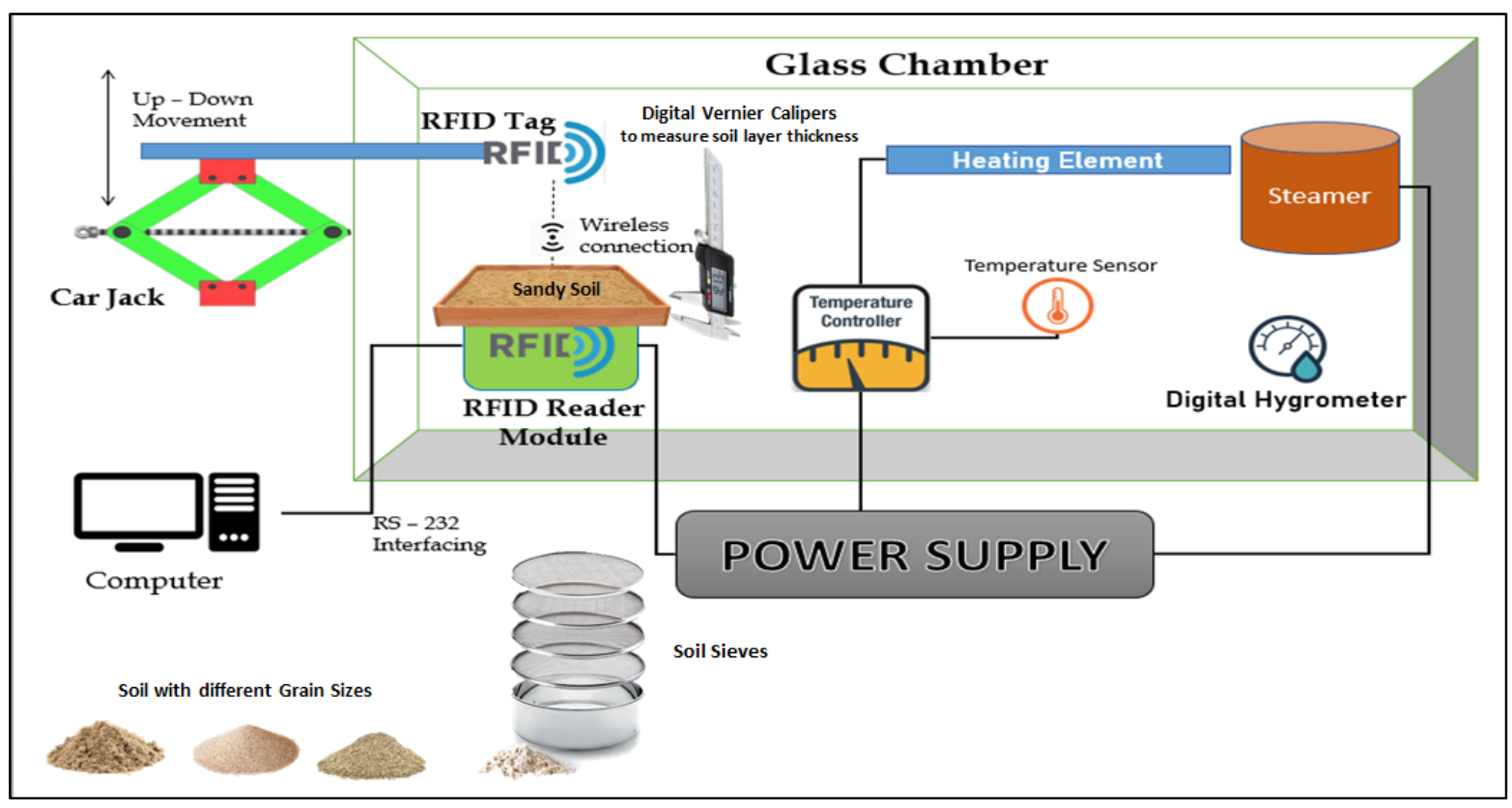

Fig. 2: Experiment setup

\subsection{RSM Technology}

RSM mathematical method is used to optimize the response. In practice, the RSM method capability is to access the best structure of the input variables for achieving the highest results with the least number of tests. This technique can be utilized in certain fields and does not have any constraint based on its application.

This study discussed the application of response surface methodology (RSM) and central composite rotatable design (CCRD) for modelling and optimization of the influence of some operating variables on the response. Four operating variables, namely ambient temperature (15-50) ${ }^{\circ} \mathrm{C}$, Soil layer (0-90) mm, Relative humidity (35-70) \% and soil grain size $(0.45-2) \mathrm{mm}$ were changed during the tests based on CCRD.

\subsection{Experiment based on RSM}

In this work, the variation in RFID system response i.e. RRSS (read range in present of sandy soil) was observed with varying input parameters i.e. SLT (soil layer thickness), SGS (soil grain size), RH (relative humidity) and TEMP (temperature).

Table 1: Experiment coding level

\begin{tabular}{|l|c|c|r|r|r|}
\hline \multirow{2}{*}{$\begin{array}{c}\text { Factors or input } \\
\text { parameters }\end{array}$} & \multicolumn{5}{|c|}{ Coded Levels } \\
\cline { 2 - 6 } & $\mathbf{- 2}$ & $\mathbf{- 1}$ & $\mathbf{0}$ & $\mathbf{1}$ & $\mathbf{2}$ \\
\hline Temperature & 15 & 20 & 25 & 40 & 50 \\
\hline Soil Layer Thickness & 0 & 25 & 45 & 65 & 90 \\
\hline Relative Humidity & 35 & 44 & 52 & 61 & 70 \\
\hline Soil Grain Size & 0.45 & 0.78 & 1.18 & 1.6 & 2 \\
\hline
\end{tabular}

Different levels of system input parameters are shown in Table 1. Experimental results obtained after executing CCRD are shown in Table 2.

Table 2: Post CCRD Experimental results

\begin{tabular}{|c|c|c|c|c|c|}
\hline Exp. Run & $\begin{array}{c}\text { Temp } \\
\text { ('C) }\end{array}$ & $\begin{array}{c}\text { SLT } \\
(\mathbf{m m})\end{array}$ & $\begin{array}{c}\text { RH } \\
\mathbf{( \% )}\end{array}$ & $\begin{array}{c}\text { SGS } \\
(\mathbf{m m})\end{array}$ & $\begin{array}{c}\text { RRSS } \\
(\mathbf{m m})\end{array}$ \\
\hline 1 & 40 & 65 & 61 & 1.6 & 110.6 \\
\hline 2 & 25 & 45 & 52 & 1.18 & 112.0 \\
\hline 3 & 25 & 45 & 52 & 1.18 & 112.0 \\
\hline 4 & 25 & 45 & 70 & 1.18 & 111.7 \\
\hline 5 & 40 & 25 & 61 & 0.78 & 112.1 \\
\hline 6 & 20 & 25 & 61 & 0.78 & 112.4 \\
\hline 7 & 40 & 65 & 61 & 0.78 & 110.3 \\
\hline 8 & 20 & 25 & 44 & 1.6 & 113.0 \\
\hline 9 & 20 & 25 & 61 & 0.78 & 112.4 \\
\hline 10 & 25 & 45 & 52 & 0.45 & 111.8 \\
\hline 11 & 25 & 45 & 52 & 1.18 & 112.0 \\
\hline 12 & 25 & 45 & 35 & 1.18 & 112.3 \\
\hline 13 & 20 & 65 & 44 & 1.6 & 111.2 \\
\hline 14 & 25 & 45 & 52 & 1.18 & 112.0 \\
\hline 15 & 25 & 45 & 52 & 2 & 112.3 \\
\hline
\end{tabular}




\begin{tabular}{|l|l|l|l|l|l|}
16 & 40 & 65 & 44 & 0.78 & 110.5 \\
\hline 17 & 20 & 65 & 61 & 1.6 & 110.9 \\
\hline 18 & 15 & 45 & 52 & 1.18 & 111.6 \\
\hline 19 & 20 & 65 & 61 & 0.78 & 110.6 \\
\hline 20 & 25 & 0 & 52 & 1.18 & 114.1 \\
\hline 21 & 25 & 90 & 52 & 1.18 & 110.0 \\
\hline 22 & 20 & 25 & 61 & 1.6 & 112.7 \\
\hline 23 & 25 & 45 & 52 & 1.18 & 112.0 \\
\hline 24 & 25 & 45 & 52 & 1.18 & 112.0 \\
\hline 25 & 40 & 25 & 44 & 1.6 & 112.7 \\
\hline 26 & 40 & 65 & 44 & 1.6 & 110.8 \\
\hline 27 & 40 & 25 & 61 & 1.6 & 112.4 \\
\hline 28 & 20 & 65 & 44 & 0.78 & 110.9 \\
\hline 29 & 25 & 45 & 52 & 1.18 & 112.0 \\
\hline 30 & 40 & 25 & 44 & 0.78 & 112.4 \\
\hline 31 & 50 & 45 & 52 & 1.18 & 111.1 \\
\hline
\end{tabular}

After the experimentation, as per the architecture matrix, ANOVA was applied, which offers quantitative results about the $\mathrm{p}$-value. The $\mathrm{p}$-value is explained as the alternative to the rejection levels to provide the lowest level of worth at which the null hypothesis would be rejected. The highest level of $\mathrm{p}$ is taken as 0.05 and the values above than 0.05 are referred as an irrelevant. $\mathrm{R}^{2}$ and $\mathrm{R}^{2}$ (adj) for this work are $98.93 \%$ and $97.99 \%$

The MINITAB 17 software is used to developed empirical correlations for Read Range for Sandy Soil (RRSS) below Eq. 1.

$$
\begin{array}{rl}
R R S S(\mathrm{~mm})=1 & 17.41+0.09 * \operatorname{Temp}\left({ }^{o} \mathrm{C}\right)-0.052 \\
& * S L T(\mathrm{~mm})-0.033 * \operatorname{RH}(\%)+0.19 \\
& * S G S(\mathrm{~mm})-0.001 *\left\{\operatorname{Temp}\left({ }^{o} \mathrm{C}\right)\right\}^{2} \\
& +0.00002 *\{S L T(\mathrm{~mm})\}^{2}+0.0001 \\
& *\{R H(\%)\}^{2}+0.01 *\{S G S(\mathrm{~mm})\}^{2} \\
& +0.00001 * \operatorname{Temp}\left({ }^{\circ} \mathrm{C}\right) * S L T(\mathrm{~mm}) \\
& ++0.0001 * \operatorname{Temp}\left({ }^{o} \mathrm{C}\right) * \operatorname{RH}(\%) \\
& +0.0001 * \operatorname{Temp}\left({ }^{o} \mathrm{C}\right) * S G S(\mathrm{~mm}) \\
& +0.000047 * \operatorname{SLT}(\mathrm{mm}) * \operatorname{RH}(\%) \\
& +0.0004 * \operatorname{SLT}(\mathrm{mm}) * S G S(\mathrm{~mm}) \\
& +0.00226 * \operatorname{RH}(\%) \\
& * S G S(\mathrm{~mm}) \ldots(1)
\end{array}
$$

\section{Result and Discussion}

MINITAB17 software was used to plot surface and contour plots. In this research work variation in RRSS (Read range in presence of Sandy Soil) were observed with four input parameters i.e. SGS (soil grain size), TEMP (temperature), RH (relative humidity) and SLT (soil layer thickness). But while plotting response curves only two control parameter were considered varying and rest two were taken at a constant value or hold value and these hold value has been sited on top right corner of each contour plot. All these hold values are the center values as mentioned in Table 1.

Fig. 3(a) to Fig. 3(f) shows the variation in LF RFID system read range in presence of sandy soil (RRSS) in between the RFID reader and tag. Variations were observed with respect to the varying input parameters i.e. Temperature - TEMP $\left(15^{\circ} \mathrm{C}\right.$ to $\left.50^{\circ} \mathrm{C}\right)$, Relative humidity - RH (35\% to 70\%), Soil layer thickness - SLT (0 mm to $90 \mathrm{~mm}$ ) and Soil grain size - SGS (.45 mm, .78 mm, 1.18 $\mathrm{mm}, 1.6 \mathrm{~mm}$, and $2 \mathrm{~mm})$.

Fig. 3(a) shows that how the RRSS get effect with varying SLT and RH, keeping other two parameters constant i.e. SLT at $45 \mathrm{~mm}$ and Temp at $25^{\circ} \mathrm{C}$. This figure clearly shows that there is sharp decrement of RRSS with increase in SLT, at the same time it also shows that RRSS is decreasing with increase in $\mathrm{RH}$ but the fall is not so sharp.

Fig. 3(b) is the contour plot for the surface plot shown in Fig. 3(a). Fig. 3(b) clearly shows that the RRSS will have its maximum value of around $117.8 \mathrm{~mm}$ when the SLT is $0 \mathrm{~mm}$ and $\mathrm{RH}$ is $35 \%$ and it will be at its minimum value of approximately $113 \mathrm{~mm}$ when the $\mathrm{RH}$ is $70 \%$ and SLT is $90 \mathrm{~mm}$.

Fig. 3(c) and Fig. 3(d) are the surface and contour plots which shows the variation in RRSS with varying TEMP and $\mathrm{RH}$ and rest two input parameters were keeping constant i.e. SLT is $45 \mathrm{~mm}$ and SGS is $1.18 \mathrm{~mm}$. Fig. 3(c) gives the clear information that RRSS is decreasing with increase in $\mathrm{RH}$ but in case of varying TEMP, it keeps on increasing with increase in TEMP from $15^{\circ} \mathrm{C}$ to $25^{\circ} \mathrm{C}$ and after that it starts decreasing with increase in TEMP till it reaches up to $50^{\circ} \mathrm{C}$. Contour plot for the parameter shown in Fig. 3(c) has been shown in Fig. 3(d). From contour plot it can be observed that RRSS achieves maximum value of $115.70 \mathrm{~mm}$ when the TEMP is $25^{\circ} \mathrm{C}$ and $43 \% \mathrm{RH}$.

Fig. 3(e) shows the variation in RRSS with respect to varying TEMP and SGS with SLT and RH remains constant at $45 \mathrm{~mm}$ and $52 \%$ respectively. Fig. 3(e) shows that RRSS keeps on increasing with increase in TEMP from $15^{\circ} \mathrm{C}$ to $25^{\circ} \mathrm{C}$ and later on it starts decreasing till the TEMP reaches up to $50{ }^{\circ} \mathrm{C}$. From the same curve we can also observe that RRSS increases with the increase in SGS. Fig. 3(f) shows the contour plot for the same parameters and it shows that RRSS will attain its maximum value of $115.65 \mathrm{~mm}$ when the SGS is of $2 \mathrm{~mm}$ and the TEMP is $25^{\circ} \mathrm{C}$. 


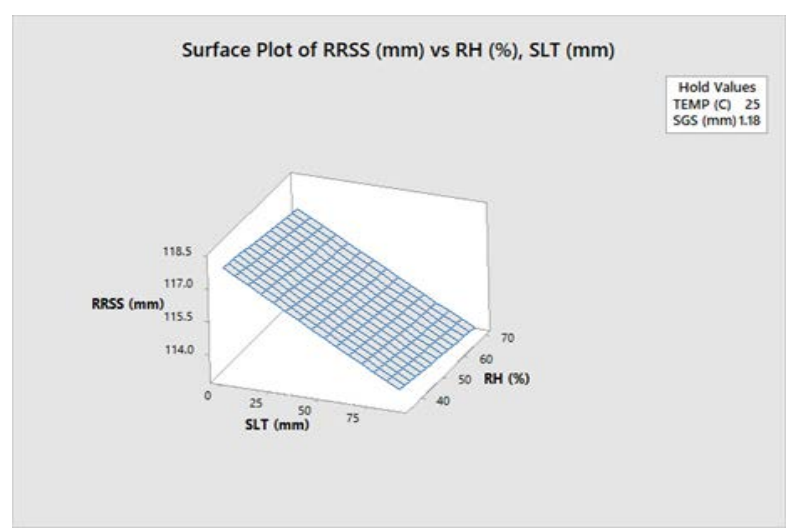

Fig. 3(a)

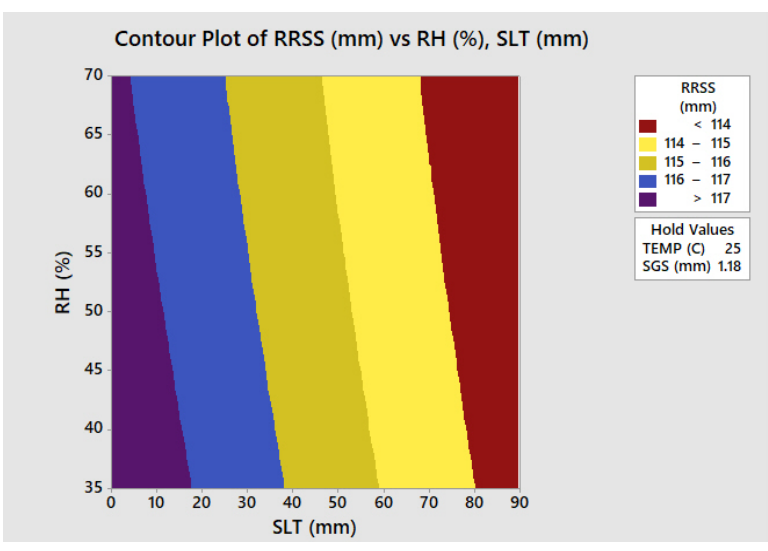

Fig. 3(b)

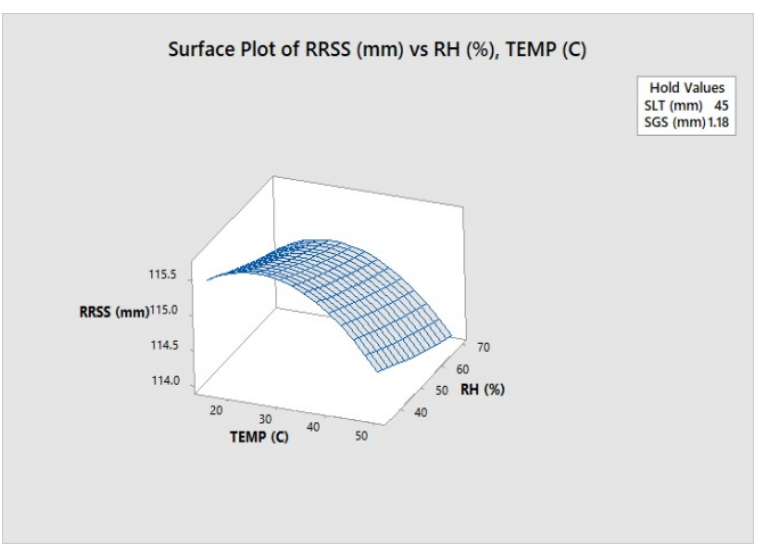

Fig. 3(c)

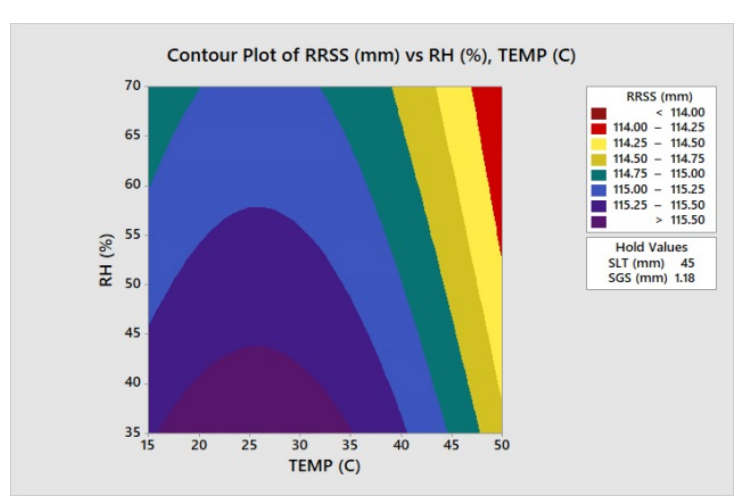

Fig. 3(d)

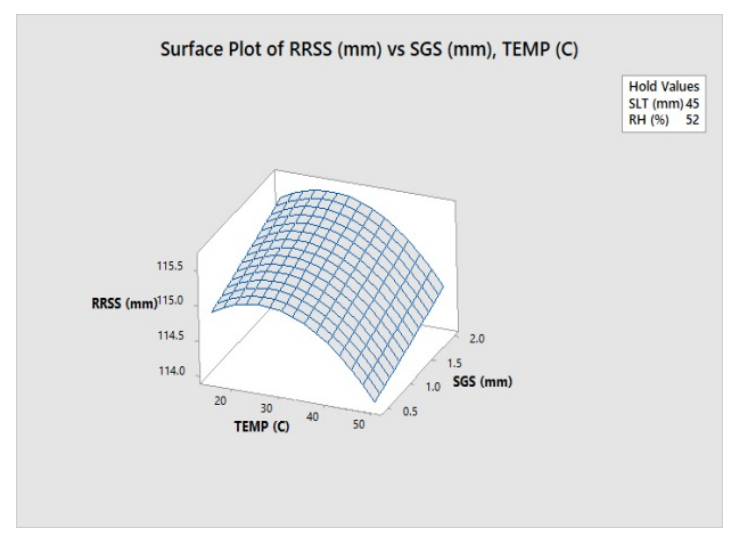

Fig. 3(e)

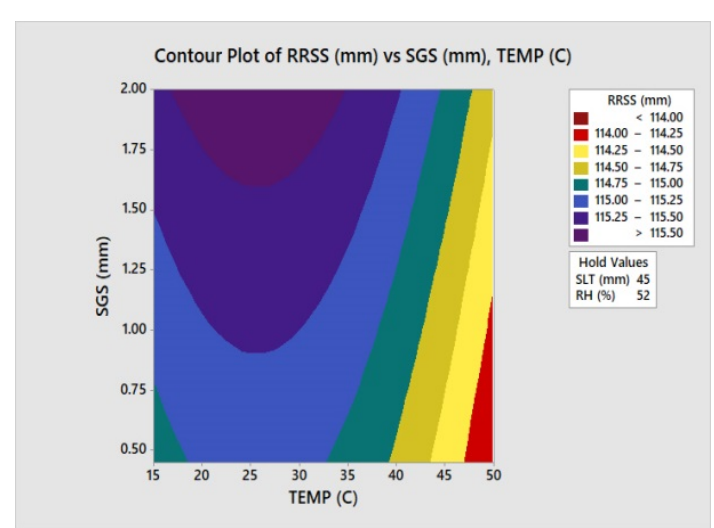

Fig. 3(f)

Fig. 3: Effect of environment parameters on read range in presence of sandy soil.

\section{Input parameter optimization and its experimental validation}

Optimized results based on RSM have been shown in the Fig. 4. From this figure it is clear that RRSS can achieve its maximum value for the combination of optimized values of input variables i.e. SLT, SGS, RH and TEMP. This research work mainly focuses on optimization of RRSS when the sandy soil is present in between the RFID tag and reader.

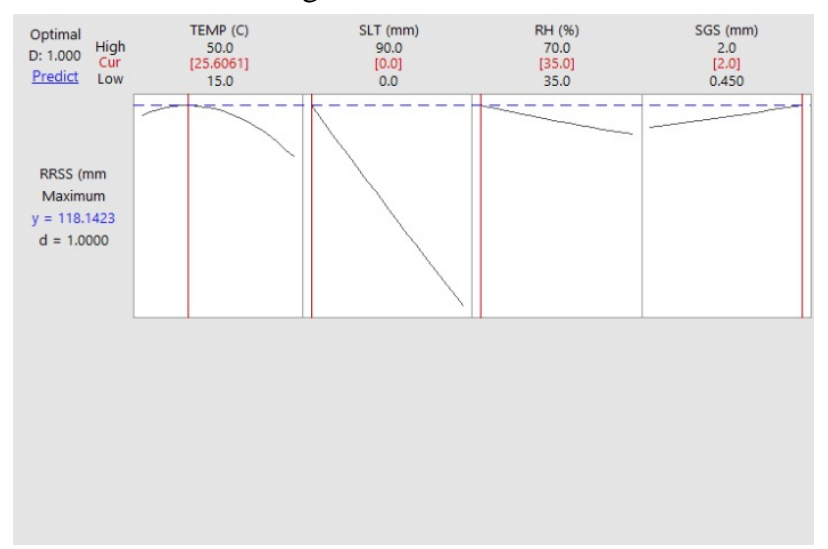

Fig. 4: Optimization plot: Impact of input parameters on responses 
From the optimization plot it is observed that best possible value of RRSS of $118.1423 \mathrm{~mm}$ can be achieved for the optimum combination of input variables i.e. TEMP, SLT, RH and SGS were found to be $25.606{ }^{\circ} \mathrm{C}, 0 \mathrm{~mm}$, $35 \%$ and $2 \mathrm{~mm}$ respectively. In this process the received value of desirability was unity and it is the favorable condition for the optimization process of RRSS.

For validation the RSM result was verified at $25.6{ }^{\circ} \mathrm{C}$ atmospheric temperature, $0 \mathrm{~mm}$ soil layer thickness, $35 \%$ relative humidity and $2 \mathrm{~mm}$ soil grain size (approximately). Table 3 shown lab experiment details and it also shows the output response for RRSS. Experimental responses and RSM optimizer values were compared.

Table 3. Experimental validation of RSM results

\begin{tabular}{|c|c|c|c|}
\hline \multicolumn{4}{|c|}{ Experimental Validation } \\
\hline RRSS at & Predicted & Actual & \% Error \\
$25.6^{\circ} \mathrm{C}$, Zero mm \\
\cline { 3 - 4 } SLT, 35\% RH, & 118.14 & 114.2 & 3.33 \\
with 2 mm SGS & & & \\
\hline
\end{tabular}

Percentage error for the RRSS response is 3.33\% and it is was well within the tolerable limits ${ }^{23)}$. Hence, the results predicted by RSM can be used for best utilize for the input setting.

\section{Conclusions}

This research work was carried out to optimize the RRSS (Read Range in presence of Sandy Soil). Statistical and experimental analyses of RRSS (Read Range in presence of Sandy Soil) were carried out with respect to four input variables i.e. SLT (Soil Layer Thickness), SGS (Soil Grain Size), TEPM (Temperature) and RH (Relative Humidity). Later the RSM mathematical modeling was used to carry out the optimization process. With the help of RSM, optimization of system parameters can be done and that too with minimum number of experiment runs (L31). From the complete study it was concluded that -

- The input parameters whose affect was observed on RRSS were Temp $\left(15^{\circ} \mathrm{C}\right.$ to $50^{\circ} \mathrm{C}$ ), RH (35\% to $70 \%$ ), SLT ( $0 \mathrm{~mm}$ to $90 \mathrm{~mm}$ ) and SGS (0.45 $\mathrm{mm}$ to $2.0 \mathrm{~mm})$.

- Best value of RRSS was attained for the optimum values of input variables i.e. Temp, RH, SLT and SGS were $25.606{ }^{\circ} \mathrm{C}, 35 \% \mathrm{RH}, 0 \mathrm{~mm}$ and $2 \mathrm{~mm}$ respectively.

- RRSS (read range in presence of sandy soil) attained its maximum value of $118.142 \mathrm{~mm}$ for the combination of optimum values of input variables.

- Validation of RSM results were carried out by multiple confirmation trials and the errors were calculated between the predicted and actual values. The calculated error was well within the tolerable limit i.e. below $5 \%$.

From the above conclusion it can be said that the low frequency RFID system can attain maximum RRSS (read range in presence of sandy soil) if it works at above mentioned optimized values of input parameters and it can work well in arid or semi-arid region where hostile environmental condition prevail and effects the RFID system detectability.

\section{Nomenclature}

RRSS Read Range in presence of Sandy Soil

SLT Soil Layer Thickness

SGS Soil Grain Size

TEMP Temperature

RH Relative Humidity

LF Low Frequency

ACA Anisotropic Conductive Adhesive

RFID Radio Frequency Identification

RSM Response Surface Methodology

\section{References}

1) By Yung-Cheng Hsieh, Hui-Wen Cheng and Yu-Ju Wu, "Key Factors Affecting the Performance of RFID Tag Antennas”, Current Trends and Challenges in RFID,(2011). DOI: 10.5772/17607.

2) Dobkin, D., \& Weigand, S., "Environmental Effects on RFID Tag Antennas”, IEEE MTT-S International Microwave Symposium Digest”,(2005). doi:10.1109/mwsym.2005.1516541

3) Dr. Tae-Hoon Kim,and Dr. Lash B. Mapa, "Investigating the Effect of Temperature in RFID Technology”, American Society for Engineering Education, (2017).

4) C. Bauer-Reich, K. C. Tan, F. Haring, N. Schneck, A. Wick, L. Berge, J. Hoey, R. Sailer, C. Ulven, “An investigation of the viability of UHF RFID for subsurface soil sensors," IEEE Int. Conf. Electro/Information Technology, 577. (2014).

5) Fangming Deng, Pengqi Zuo, Kaiyun Wen, Xiang $\mathrm{Wu}$, "Novel soil environment monitoring system based on RFID sensor and LoRa “, Computers and Electronics in Agriculture, 169(2020). DO10.1016/j.compag.2019.105169. 
6) K. Saarinen, T. Björninen, L. Ukkonen, and L. Frisk, "Reliability Analysis of RFID Tags in Changing Humid Environment,” IEEE Trans. Compon. Packag. Manuf. Technol., 4, 77 (2014).

7) Sari Linnea Merilampi, Johanna Virkki, Leena Ukkonen \& Lauri Sydänheimo, “Testing the effects of temperature and humidity on printed passive UHF RFID tags on paper substrate”, International Journal of Electronics, 101:5711(2014).DOI: 10.1080/00207217.2013.794491.

8) J. Alarcon, R. Saba, M. Egels, and P. Pannier, "A flexible UHF RFID tag for harsh environments," IEEE Int. Conf. RFID Technologies and Applications,267(2012).

9) S. Manzari, C. Occhiuzzi, S. Nawale, A. Catini, C. D. Natale, and G. Marrocco, "Humidity Sensing by Polymer-Loaded UHF RFID Antennas,” IEEE Sens. J., 12 2851( 2012).

10) K. Dastoori, B. Makin, S. Bappoo,"The effectiveness of passive RFID Tags in the presence of charged particles”, Journal of Electrostatics, 67, Issues 2, 468, (2009)

11) Hong, Yizhi, Chen, Hao, Kannan, Pranav, Harding, Brian, Rahmani, Samina, Zoghi, Ben Mannan, M. Sam, "Development of a Passive Radio Frequency Identification-Based Sensor for External Corrosion Detection," International Journal of Engineering Research \& Innovation, 8 (2016).

12) S. Choudhary, H. Purohit, A. Sehgal and A. Kaushik, "Performance Study of Detectability of RFID System With Varying Atmospheric Conditions," 2019 IEEE 10th Annual Ubiquitous Computing, Electronics \& Mobile Communication Conference (UEMCON), New York City, NY, USA, 0940 (2019).

13) M. Le Breton Laurent Baillet, Eric Larose, Etienne Rey, Philippe Benech, Denis Jongmans, Fabrice Guyoton, "Outdoor meteorological effects on UHF RFID phase shift: Experimental simulations," 2017 IEEE International Conference on RFID (RFID), Phoenix, AZ, 103 (2017).

14) Dukyil, Abdulsalam, Mohammed, Ahmed, Darwish, Mohamed, "Design and optimization of an RFID-enabled Passport Tracking System”, Journal of Computational Design and Engineering, (2017). DO 10.1016/j.jcde.2017.06.002.

15) E. M. Amin, R. Bhattacharyya, S. Kumar, S. Sarma, and N. C. Karmakar, "Towards low-cost resolution optimized passive UHF RFID light sensing," WAMICON, 1 (2014).
16) Jian, Ming-Shen, and Jain-Shing Wu., "RFID applications and challenges", Radio Frequency Identification from System to Applications (2013).

17) Li Zhenzhong, Mrad Nezih, Xiao George, Ono Yuu, Liu Guocheng, Ban Dayan, "Effects Of Temperature And Humidity On Uhf Rfid Performance”, Smart Materials, Structures \& Ndt In Aerospace Conference NDT In Canada,(2011).

18) Jussi Nummela, Leena Ukkonen And Lauri Sydänheimo, "The Effect of Low Temperature on Passive UHF RFID Tags", Proceedings of the 4th WSEAS International Conference on REMOTE SENSING, (2008).

19) Chonggang Wang, Mahmoud Daneshmand, Kazem Sohraby, "Optimization of tag reading performance generation-2 RFID protocol Computer Communications, 321346 (2009).

20) S. E. Watkins, T. M. Swift, and M. J. Molander, “RFID Instrumentation in a Field Application,” IEEE Region 5 Technical Conf., 400 (2007).

21) Luvisi Andrea, Panattoni, Alessandra, Materazzi, Alberto, "RFID temperature sensors for monitoring soil solarization with biodegradable films", Computers and Electronics in Agriculture, 123, 135, (2016). DO - 10.1016/j.compag.2016.02.023.

22) Pichorim, S., Gomes, N., Batchelor, J., "Two solutions of soil moisture sensing with RFID for landslide monitoring”, Sensors 18, 2452 (2018).

23) HS Pali, A Sharma, Y Singh, N Kumar, "Sal biodiesel production using Indian abundant forest feedstock", Fuel, (2020).

24) Abhishek Sharma, Yashvir Singh, Nishant Kumar Singh, Amneesh Singla, Hwai Chyuan Ong, Wei-Hsin Chen, "Effective utilization of tobacco (Nicotiana Tabaccum) for biodiesel production and its application on diesel engine using response surface methodology approach”, Fuel, (2020).

25) Fachransjah Aliunir, Teuku Yuri M. Zagloel, and Romadhani Ardi, "Discrete-Event Simulation and Optimization of Spare Parts Inventory and Preventive Maintenance Integration Model Considering Cooling Down and Machine Dismantling Time Factor", EVERGREEN Joint Journal of Novel Carbon Resource Sciences \& Green Asia Strategy, 07 79-85 (2020). 